\title{
浅谈小学低年级语文写话教学的点滴做法
}

张同菊

山东省济南市无影山小学

DOI:10.32629/jief.v2i6.1085

[摘 要] 随着新课程理念提出以来, 写话教学的重要性被教师广泛认可。写话教学作为写作的起步阶段从低年级开始训练, 对于学生的写作 培养具有重要意义, 首先能够激发学生对写作的兴趣, 在此基础上引导学生将自己的所遇所见用语言表达出来, 这样才能更好的提高学生的 写作水平。

[关键词] 小学语文; 低年级; 写话教学; 策略

中图分类号: G633.3 文献标识码: A

写话的核心是如何引导学生用语言文字将自己所要表达的事物进行 表现, 这对于学生的写作能力和表达能力具有一定的要求。尤其是小学 低年级的学生, 他们的思维发展还不够成熟, 在语言表达上的能力也需 要进一步发展, 更需要教师在教学过程中制定科学合理的教学策略进行 引导, 这样才能通过写话教学促进学生的写作水平提高。

\section{1 当前小学语文低年级写话教学中存在的问题}

1.1 写话教学的内容没有联系实际生活

语文学科与生活具有紧密的联系, 写作也是学生对生活的思考。但 在传统的语文写话教学过程中, 大多数教师仅仅以教材为依托, 没有注 重为学生创设生活化的情境, 这样的方式导致学生难以获得良好的情感 体验和感悟, 在写话训练的过程中只能靠自己的想象进行编造, 最终导 致与实际生活相脱节, 影响了学生的写作体验, 也影响了写作质量。

1.2 教师没有实现对学生的有效引导

低年级的学生在学习过程中更需要教师的有效引导, 写话教学也是如 此, 但大多数教师在教学过程中没有重视写话教学的作用, 设计的教学策 略也难以激发学生的训练兴趣, 进一步影响写话教学的质量和效率。如果 教师在教学过程中不制定明确的写话训练目标, 指在教学过程中关注学生 的写作技巧提升, 这样的方式会导致学生对写话训练产生抵触情绪。

\section{2 提高小学低年级语文写话教学有效性的策略}

2.1 为学生创设生活化的学习情境

学生只有在实际生活中进行体验和感悟, 才能拥有真情实感, 并且 在教师创设的学习情境中进行表达和用语言文字进行表现。要想提高学 生写话训练的有效性, 进一步提高写话训练的质量, 教师首先要为学生 创设生活化的学习情境, 这样的方式能够吸引学生的兴趣, 更加符合低 年级小学生的身心发展规律; 另一方面, 为学生创设生活化的学习情境, 能够为学生提供发展思维的具体平台, 学生在联系生活实际的过程中能 够拥有更加深刻的情感体验, 更利于学生在写话训练过程中运用语言文 字进行表现, 避免学生在写作过程中胡编乱造的情况。

以部编版小学一年级语文课程《秋天》为例。教师在进行写话训练 时从课前导入开始为学生逐渐呈现出秋天的美丽景色, 在课前导入阶段, 教师播放了美丽秋天的景色, 一边引导学生欣赏画面, 一边运用语言让 学生进入情境 “大自然是一副多姿多彩的画卷, 在大自然中我们能更好 的发现美, 感受美, 㫿! 秋天来了, 我们一起去欣赏那些迷人的景色吧”。 教师一边引导学生进入情境, 一边为学生展示秋天的美景, 如秋天的落 叶、南归的大雁、丰收的景象, 让学生在不断体验的过程中进行感悟。 除此之外, 在条件允许的情况下, 教师还可以带领学生深入自然, 亲身 体验秋天的气息, 和秋天的美丽景色, 在此过程中鼓励学生表述自己对 秋天的印象, 通过这样的方式学生在具体情境中能够有更好的情感体验, 在进行写作训练的过程中也更加有话可说。

\section{2 在师生互动过程中实现有效引导}

小学阶段的学生正处在身心发展的初始阶段, 他们的学习活动处在 无意识阶段, 因此, 对小学低年级阶段的学生进行教学, 离不开教师进 行引导, 在引导过程中, 教师要根据学生的身心发展规律制定有效的教 学策略, 首先让学生拥有喜欢训练的兴趣, 逐步培养其主动意识, 在此 基础上通过教学活动再进行深入引导, 并且教给学生相应的方法, 使学 生从 “想写” 变成 “爱写”。在教学实践中, 教师可以通过教学互动, 让 学生在引导过程中不断动脑筋思考, 跟随教师的引导不断发展自身的思 维, 从而进行更好的表达, 运用互动教学策略, 还可以让学生将自己带 入到教师设计的情境之中, 学生拥有身临其境的体验, 能够更好的丰富 自身的表达体系。

以部编版小学语文一年级课程《操场上》为例。教师在教学过程中, 首先创设情境进行课前导入, 为学生准备了皮球、球拍等相应的道具, 再用 PPT 出示课文情境图, 对学生进行启发引导 “小朋友们大家看看, 图上的小朋友在哪儿呢?”, 学生能根据教师的问题说出答案, 教师再继 续引导 “小朋友们在操场上干什么呢? ”, 让学生根据 PPT 出示的课文情 境回答, 总结学生的答案之后, 教师出示了相关的道具, 再一次引导学 生 “老师手上有球拍、有皮球，你会拿着它在操场上干些什么呢？”, 通 过这样的方式, 让学生在教师的启发下, 不断的发散思维, 根据自身的 想象和实际体验进行语言文字的表现。

除此之外, 教师在教学过程中还要制定有效的评价机制, 对学生进 行积极的评价和鼓励, 让学生获得学习自信, 并且在此过程中不断发现 自身的缺点加以改正，通过多元化的评价方式，促进写话训练的有效性。 在实践过程中, 教师还可以为学生构建多元化的评价主体积极发挥学自 身的优势, 通过有效的评价机制, 让学生在自我评价、相互评价的过程 中不断进步。

\section{3 结语}

小学低年级的学生由于身心发展的限制, 需要教师在教学过程中进 行有效的引导, 才能初步养成学习意识和学习习惯, 并且通过教师的教 学活动引导, 才能写出相应的方法。因此教师要充分发挥自身的引导作 用, 根据学生的身心发展规律, 制定相应的教学策略, 通过不断的引导, 激发学生的学习兴趣, 让学生在欲望的驱使下培养写话训练的意识, 进 一步拥有相应的能力，最终提高写话训练的有效性和质量。

\section{[参考文献}

[1] 托欢高. 小学语文低年级写话教学策略 [J]. 名师在 线,2019(34):29-30.

[2]蒋桂荣.浅析小学低年级语文写话教学存在的问题 [J].新课程研 究,2017(08):15-16.

[3]杜生䎦.浅谈小学语文写字教学的多样性[J].新课程,2020(38):59. 